\title{
The clinical value of high-density lipoprotein in the evaluation of new coronavirus pneumonia
}

\author{
Shipeng Huang ${ }^{A-C, F}$, Congyang Zhou ${ }^{B, C, F}$, Zheng Yuann ${ }^{B, C, F}$, Hui Xiao ${ }^{B, C, F}$, Xiaoping Wu ${ }^{A, D-F}$ \\ The First Affiliated Hospital of Nanchang University, China \\ A - research concept and design; $\mathrm{B}$ - collection and/or assembly of data; $\mathrm{C}$ - data analysis and interpretation; \\ $D$ - writing the article; $E$ - critical revision of the article; $F$ - final approval of the article
}

Address for correspondence

Xiaoping Wu

E-mail:xiaopeng_wu@tom.com

Funding sources

None declared

Conflict of interest

None declared

Received on June 16,2020

Reviewed on June 17, 2020

Accepted on November 18, 2020

Published online on February 11, 2021

\section{Abstract}

Background. The new coronavirus pneumonia (NCP, COVID-19) outbreak began in Wuhan in December 2019. The new coronavirus (2019 novel coronavirus (2019-nCoV)) can cause multiple organ damage, mainly to lung tissue, and induce inflammation in the body.

Objectives. To investigate the changes of high-density lipoprotein (HDL) level in patients with COVID-19 and assess its value in the evaluation and prognosis of this disease.

Materials and methods. This paper is a cross-sectional retrospective study. Eighty-six severe COVID-19 patients, 132 non-severe COVID-19 patients and 76 healthy individuals (control group) were recruited to measure triglyceride (TG), total cholesterol (TC), high-density lipoprotein cholesterol (HDL-C), and low-density lipoprotein cholesterol (LDL-C) using enzyme-coupled colorimetry.

Results. The serum HDL-C level in COVID-19 group was $1.02 \pm 0.28 \mathrm{mmol} / \mathrm{L}$ which was significantly lower than in control group $(1.52 \pm 0.55 \mathrm{mmol} / \mathrm{L})(\mathrm{p}<0.05)$. In addition, the serum HDL-C level in severe COVID-19 group was $0.83 \pm 1.67 \mathrm{mmol} / \mathrm{L}$, which was significantly lower than that in non-severe COVID-19 group $(1.15 \pm 0.27 \mathrm{mmol} / \mathrm{L})(p<0.05)$.

Conclusions. Changes in HDL levels in patients with COVID-19 can reflect the severity of the disease and have a clinical significance in establishing the prognosis.

Key words: blood lipids, critical illness, new coronavirus pneumonia, high-density lipoprotein cholesterol

Cite as

Huang S, Zhou C, Yuan Z, Xiao H, Wu X. The clinical value

of high-density lipoprotein in the evaluation of new

coronavirus pneumonia. Adv Clin Exp Med. 2021;30(2):153-156.

doi:10.17219/acem/130606

DOI

10.17219/acem/130606

Copyright

Copyright by Author(s)

This is an article distributed under the terms of the

Creative Commons Attribution 3.0 Unported (CC BY 3.0)

(https://creativecommons.org/licenses/by/3.0/) 


\section{Background}

The new coronavirus pneumonia (NCP, COVID-19) outbreak began in Wuhan in December 2019. ${ }^{1}$ It can cause multiple organ damage, mainly to lung tissue, and induce inflammation in the body. ${ }^{1,2}$ In recent years, more and more studies have shown that plasma high-density lipoprotein (HDL) not only participates in reverse transport of cholesterol, but also widely affects the inflammatory response of the body. ${ }^{3}$

\section{Objectives}

The purpose of this study was to analyze the changes of HDL levels in patients with COVID-19 and the clinical value of this measurement in the evaluation and prognosis of this disease.

\section{Materials and methods}

\section{General information}

Cross-sectional retrospective analysis was performed in the present study. All cases were divided into 3 groups: severe COVID-19 group, non-severe COVID-19 group and healthy control group. The severe group included 86 patients with severe/critical COVID-19, of an average age of $54.36 \pm 12.61$ years, while the non-severe group consisted of 132 mild COVID-19 patients, of an average age of $44.02 \pm 17.13$ years. Seventy-six healthy individuals with an average age of $47.73 \pm 8.68$ years, receiving medical examinations, served as the healthy control group. The exclusion criteria were as follows: malignant tumors, severe head trauma and other diseases. This study was approved by the ethics committee of our hospital and all participants signed the informed consent prior to the study.

\section{Diagnostic criteria and classification criteria}

All COVID-19 patients enrolled met the diagnostic criteria of the New Coronavirus Pneumonia Diagnosis and Treatment Program (trial version 7) issued by the National Health Commission of China on March 4, 2020. ${ }^{4}$ All cases were confirmed using the new coronavirus nucleic acid test through real-time fluorescent reverse-transcription polymerase chain reaction (RT-PCR). Patients were classified according to the new version of the diagnosis and treatment plan into the following categories: 1) light or mild clinical symptoms, no pneumonia manifestations in the imaging; 2) common type of the disease, with symptoms of fever, respiratory tract, etc. (pneumonia visible in the imaging); 3) severe disease, meeting any of the following criteria: shortness of breath, breathing frequency $\geq 30$ times/min; blood oxygen saturation $\left(\mathrm{SO}_{2}\right) \leq 93 \%$; arterial blood oxygen partial pressure $\left(\mathrm{PaO}_{2}\right)$ /oxygen absorption concentration $\left(\mathrm{FiO}_{2}\right) \leq 300 \mathrm{~mm} \mathrm{Hg}$ at rest; 4) critical form of the disease, meeting any of the following criteria: respiratory failure, mechanical ventilation required; shock (or combined with other organ failure), requiring intensive care unit (ICU) treatment.

\section{Research methods}

Cases that met the diagnostic criteria for new coronavirus pneumonia were classified according to the New Coronavirus Pneumonia Diagnosis and Treatment Program (trial version 7), and patients from categories 1 and 2 were included into the non-severe group, while patients from categories 3 and 4 were included into the severe group. Venous blood was collected from all enrolled subjects on the $1^{\text {st }}$ day of admission to measure triglycerides (TG), total cholesterol (TC), high-density lipoprotein cholesterol (HDL-C), and low-density lipoprotein cholesterol (LDL-C) levels using enzyme-coupled colorimetric method.

\section{Statistical processing}

The statistical analysis was carried out using SPSS v. 20.0 software (IBM Corp., Armonk, USA). The countable data was expressed as a percentage and assessed with a $\chi^{2}$ test. The measurement data was displayed as mean \pm standard deviation (SD) and evaluated with the Student's t-test. A value of $\mathrm{p}<0.05$ indicated statistically significant difference.

\section{Results}

The serum HDL-C levels in the COVID-19 group and healthy control group were $1.02 \pm 0.28 \mathrm{mmol} / \mathrm{L}$ and $1.52 \pm 0.55 \mathrm{mmol} / \mathrm{L}$, respectively. After data was analyzed using the Student's t-test, the serum HDL-C levels in the COVID-19 group turned out to be significantly

Table 1. Comparison of blood routine, blood glucose and blood lipid results between COVID-19 group and healthy control group

\begin{tabular}{|l|c|c|}
\multicolumn{1}{|c|}{ Parameters } & $\begin{array}{c}\text { COVID-19 } \\
\text { group }\end{array}$ & $\begin{array}{c}\text { Healthy } \\
\text { control group }\end{array}$ \\
\hline Age [years] & $48.19 \pm 16.33$ & $47.73 \pm 8.68$ \\
\hline White blood cells $\left[\times 10^{9} / \mathrm{L}\right]$ & $6.77 \pm 3.59$ & $6.14 \pm 2.05$ \\
\hline Absolute value of lymphocytes $\left[\times 10^{9} / \mathrm{L}\right]$ & $1.09 \pm 0.81$ & $1.92 \pm 0.74$ \\
\hline Absolute value of neutrophils $\left[\times 10^{9} / \mathrm{L}\right]$ & $5.21 \pm 3.59$ & $3.56 \pm 1.33$ \\
\hline Total cholesterol $[\mathrm{mmol} / \mathrm{L}]$ & $3.81 \pm 0.82^{\mathrm{a}}$ & $4.64 \pm 1.00$ \\
\hline Triglyceride $[\mathrm{mmol} / \mathrm{L}]$ & $1.42 \pm 1.38^{\mathrm{a}}$ & $1.64 \pm 1.12$ \\
\hline High-density lipoprotein $[\mathrm{mmol} / \mathrm{L}]$ & $1.02 \pm 0.28^{\mathrm{a}}$ & $1.52 \pm 0.55$ \\
\hline Low-density lipoprotein $[\mathrm{mmol} / \mathrm{L}]$ & $2.46 \pm 0.77^{\mathrm{a}}$ & $2.55 \pm 0.75$ \\
\hline
\end{tabular}


Table 2. Comparison of blood lipid results in severe group, non-severe group and healthy control group

\begin{tabular}{|l|c|c|c|c|}
\hline \multicolumn{1}{|c|}{ Group } & $\begin{array}{c}\text { Number } \\
\text { of patients }\end{array}$ & $\begin{array}{c}\text { TC } \\
{[\mathrm{mmol} / \mathrm{L}]}\end{array}$ & $\begin{array}{c}\text { TG } \\
{[\mathrm{mmol} / \mathrm{L}]}\end{array}$ & $\begin{array}{c}\text { HDL-C } \\
{[\mathrm{mmol} / \mathrm{L}]}\end{array}$ \\
\hline Severe & 86 & $3.65 \pm 0.75$ & $1.91 \pm 1.87$ & $0.83 \pm 1.67$ \\
\hline Non-severe & 132 & $3.93 \pm 0.84$ & $1.1 \pm 0.79$ & $1.15 \pm 0.27^{*}$ \\
\hline Healthy control & 76 & $4.64 \pm 1.01$ & $1.64 \pm 1.12$ & $2.52 \pm 0.71$ \\
\hline
\end{tabular}

* compared with the severe group $(p<0.05)$; ${ }^{* *}$ compared with the non-severe group $(p<0.05)$.

lower than those in the healthy control group $(\mathrm{p}<0.05)$ (Table 1). The HDL-C levels in severe COVID-19 group and non-severe COVID-19 group were $0.83 \pm 1.67 \mathrm{mmol} / \mathrm{L}$ and $1.15 \pm 0.27 \mathrm{mmol} / \mathrm{L}$, respectively. The HDL-C level in the non-severe group was significantly higher than in the severe group, and the statistical results were significantly different $(\mathrm{p}<0.05)$ (Table 2$)$.

\section{Discussion}

The COVID-19 is caused by a new coronavirus (2019$\mathrm{nCoV}$ ) infection and the disease progresses rapidly. At the same time, general population susceptibility and significant infectivity can be observed. ${ }^{5}$ A number of studies have shown that 2019-nCoV can induce a cytokine storm after invading the body and aggravating the inflammatory response. Interleukin 2 (IL-2), granulocyte colony stimulating factor (G-SCF) and macrophage inflammatory protein (MIP-1a) as well as tumor necrosis factor $\alpha$ (TNF- $\alpha)$ and other inflammatory factors have increased to varying degree in patients' plasma. ${ }^{6,7}$ The COVID-19 is mainly caused by lung tissue lesions and patients present abnormally increased inflammatory factors, leading to overactivation of immune cells, which accumulate and activate in the lung tissue, resulting in diffuse damage to pulmonary capillary endothelial cells and alveolar epithelial cells. Pulmonary damage produces in turn a large amount of inflammatory exudate that eventually blocks the bronchial tubes at all levels, causing continuing deterioration of lung function, leading to acute respiratory distress syndrome (ARDS) and respiratory failure. ${ }^{7,8}$ The results of our study showed that the level of HDL-C in the COVID-19 patients was significantly lower than in the healthy control group ( $\mathrm{p}<0.05$ ). At the same time, the level of HDL-C in the severe COVID-19 group was significantly lower than in the non-severe COVID-19 ( $\mathrm{p}<0.05)$. This shows that blood lipid levels, especially HDL-C levels, vary in patients with COVID-19. The severity of this disease can affect the fluctuation of HDL-C levels. Severe COVID-19 patients have significantly lower HDL-C levels than non-severe patients. Therefore, the changes of HDL-C level can be used as a predictor of the severity of COVID-19.

Among various lipoproteins in the body, HDL has the smallest volume and the highest density. It mainly reverses cholesterol from the peripheral tissues to the liver for further recycling or excretion in the form of cholic acid. ${ }^{9}$ However, in recent years, the role of HDL in inflammatory infection has been gradually better understood. Some studies have shown that HDL can prevent the activation of peripheral blood monocytes and macrophages lipopolysaccharides (LPS) and lipid wall phosphates (LTA), thereby reducing TNF- $\alpha$ and interleukin $1 \beta$ (IL-1 $\beta$ ) synthesis and secretion. ${ }^{10}$ When the body is infected, LPS, which constitute the main component of endotoxin, are released from the outer cell membrane to form a complex with HDL, thereby achieving the effect of neutralizing toxicity and reducing inflammation; HDL levels also decrease. ${ }^{11}$ The HDL and LPS are combined and consumed in the body. Once exhausted, the patient's inflammatory response is difficult to be effectively controlled, eventually leading to multiple organ dysfunction or even death.

Many studies have shown that HDL can inhibit the combination of various types of viruses and host cells, including enveloped and non-enveloped DNA and RNA viruses, such as Japanese encephalitis virus, rubella virus, Epstein-Barr virus, herpes simplex virus, human immunodeficiency virus (HIV), coxsackievirus, , poliovirus, and other viruses. In the early stage of viral infection, HDL exerted antiviral activity, mainly inhibiting the penetration of the virus into the cells after it was adsorbed. ${ }^{12}$ Another study showed that the function of HDL isolated from mice infected with influenza A is impaired and its anti-inflammatory and antioxidant properties are reduced ${ }^{13}$; further injection of D-4F ApoAI mimic peptide into infected mice can reduce the inflammation in the lungs and inhibit the production of IL- 6 and prevent macrophages from entering the arteries. ${ }^{14}$ The D-4F ApoAI mimic peptide also has antiviral activity and can reduce influenza virus titer by $50 \% .{ }^{15}$ The above research provides new ideas for inhibiting 2019-nCoV. Perhaps exogenous HDL can be used as a kind of antiviral treatment. It also proves that the level of HDL in patients with COVID-19 can reflect the disease severity.

The HDL synthesis occurs mainly through the liver and small intestine, and most of the severe COVID-19 patients have impaired liver function and small intestinal mucosal ischemia, so HDL synthesis is also reduced; at the same time, intake of large amounts of carbonate compounds can accelerate the decomposition of proteins in HDL. ${ }^{16}$ Therefore, treatment of severe COVID-19 patients should include maintaining liver and intestinal mucosal function, and appropriately reducing carbohydrate intake, so as to ensure the synthesis of HDL and improve the prognosis. 


\section{Conclusions}

The HDL, as part of the natural immunity of the body, has antiviral and anti-inflammatory properties. The results of this study show that changes in HDL levels in patients with COVID-19 can reflect the disease severity and have clinical significance in assessing the prognosis. The lower HDL-C levels, the worse the prognosis. At the same time, HDL-C has certain application prospects in the treatment of COVID-19. This study demonstrated the change of HDL levels in patients with COVID-19, providing an important reference for the clinical diagnosis and treatment. However, other potential biomarkers need to be further investigated to enable a comprehensive understanding of COVID-19.

\section{ORCID iDs}

Shipeng Huang (1) https://orcid.org/0000-0002-5609-3547 Congyang Zhou (1) https://orcid.org/0000-0002-5595-1036 Zheng Yuan (10) https://orcid.org/0000-0002-2148-9891 Hui Xiao (1) https://orcid.org/0000-0001-8732-120X Xiaoping Wu (1) https://orcid.org/0000-0003-0138-8636

\section{References}

1. Lu R, Zhao X, Li J, et al. Genomic characterization and epidemiology of 2019 novel coronavirus: Implications for virus origins and receptor binding. Lancet. 2020;395(10224):565-574. doi:10.1016/s0140-6736 (20)30251.8

2. Huang C, Wang Y, Li X, et al. Clinical features of patients infected with 2019 novel coronavirus in Wuhan, China. Lancet. 2020;395(10223): 497-506. doi:10.1016/S0140-6736(20)30183-5

3. Florentin M, Liberopoulos EN, Wierzbicki AS, et al. Multiple actions of high-density lipoprotein. Curr Opin Cardiol. 2008;23(4):370-378.

4. National Health Commission. New Coronavirus Pneumonia Diagnosis and Treatment Program (trial $7^{\text {th }}$ edition). http://www.gov.cn/ zhengce/zhengceku/2020-01/28/content_5472673.htm. Accessed on May 15, 2020.
5. Zhou P, Yang X, Wang X, et al. Discovery of a novel coronavirus associated with the recent pneumonia outbreak in humans and its potential bat origin. bioRxiv. 2020:2020-2021. https://doi.org/10.1101/ 2020.01.22.914952

6. Chen N, Zhou M, Dong X, et al. Epidemiological and clinical characteristics of 99 cases of 2019 novel coronavirus pneumonia in Wuhan, China: A descriptive study. Lancet. 2020;395(10223):507-513. doi:10. 1016/S0140-6736(20)30211-7

7. Wang DW, Hu B, Hu C, et al. Clinical characteristics of 138 hospitalized patients with 2019 novel coronavirus-infected pneumonia in Wuhan, China. JAMA. 2020;323(11):1061-1069. doi:10.1001/JAMA.2020.1585

8. Hui DSC, Zumla A. Severe acute respiratory syndrome: Historical, epidemiologic, and clinical features. Infect Dis Clin North Am. 2019;33(4): 869-889. doi:10.1016/j.idc.2019.07.001

9. Kapur NK, Ashen D, Blumenthal RS. High density lipoprotein cholesterol: An evolving target of therapy in the management of cardiovascular disease. Vasc Health Risk Manag. 2008;4(1):39-57. doi:10.2147/ vhrm.2008.04.01.39

10. Casas AT, Hubsch AP, Rogers BC, Doran JE. Reconstituted high-density lipoprotein reduces LPS-stimulated TNF-a. J Surg Res. 1995;59(5): 544-552. doi:10.1006/jsre.1995.1204

11. Thompson PA, Tobias PS, Viriyakosol S, Kirkland TN, Kitchens RL. Lipopolysaccharide (LPS)-binding protein inhibits responses to cellbound LPS. J Biol Chem. 2003;278(31):28367-28371. doi:10.1074/jbc. M302921200

12. Singh IP, Chopra AK, Coppenhaver DH, Ananatharamaiah GM, Baron S. Lipoproteins account for part of the broad non-specific antiviral activity of human serum. Antiviral Res. 1999;42(3):211-218. doi:10.1016/s0166-3542(99)00032-7

13. Van Lenten BJ, Wagner AC, Nayak DP, Hama S, Navab M, Fogelman AM. High-density lipoprotein loses its anti-inflammatory properties during acute influenza A infection. Circulation. 2001;103(18):2283-2288. doi:10.1161/01.CIR.103.18.2283

14. Van Lenten BJ, Wagner AC, Anantharamaiah GM, et al. Influenza infection promotes macrophage traffic into arteries of mice that is prevented by D-4F, an apolipoprotein A-I mimetic peptide. Circulation. 2002;106(9):1127-1132. doi:10.1161/01.CIR.0000030182.35880.3E

15. Van Lenten BJ, Wagner AC, Navab M, et al. D-4F, an apolipoprotein a-I mimetic peptide, inhibits the inflammatory response induced by influenza A infection of human type Il pneumocytes. Circulation. 2004;110(20):3252-3258. doi:10.1161/01.CIR.0000147232.75456.B3

16. Wu A, Thiemermann CJC. High-density lipoprotein in sepsis and septic shock: Metabolism, action and therapeutic applications. Shock. 2004;(32):10-221. doi:10.1097/01.shk.0000111661.09279.82 